\title{
Perfil epidemiológico de HIV/AIDS no Brasil com base nos dados provenientes do DataSUS no ano de $2021^{1}$
}

\author{
Epidemiological profille of HIV/AIDS in Brazil based on data from DataSUS in the year 2021 \\ Perfil epidemiológico de VIH/SIDA en Brasil con base a los datos provenientes del DataSUS en el
}

año de 2021

Tamires Saraiva Aguiar

ORCID: https://orcid.org/0000-0003-0422-5357

Universidade Potiguar, Brasi

E-mail: tamiresaguiar@hotmail.com

Michelle Carneiro Fonseca

ORCID: https://orcid.org/0000-0003-4274-1571

Universidade Federal do Rio Grande do Norte, Brasil

E-mail: michellecf3112@hotmail.com

Mariana César dos Santos

ORCID: https://orcid.org/0000-0003-2782-1776

Universidade Federal do Rio Grande do Norte, Brasil

E-mail: marianacesar20@yahoo.com.br

Giancarlo Paiva Nicoletti

ORCID: https://orcid.org/0000-0002-6173-2649 Centro Universitário Natalense, Brasil

E-mail: giancarlo_nicoletti1@hotmail.com

Daniella Santos Guedes Alcoforado

ORCID: https://orcid.org/0000-0001-9384-4939 Universidade Federal do Rio Grande do Norte, Brasil

E-mail: daniellasga@gmail.com

Sueleide Cristina Dantas dos Santos

ORCID: https://orcid.org/0000-0002-6106-5233 Universidade Federal do Rio Grande do Norte, Brasil

E-mail: sueleidedantas@gmail.com

Maria de Lourdes Pontes Neta

ORCID: https://orcid.org/0000-0002-6970-2225 Universidade Federal do Rio Grande do Norte, Brasil

E-mail: mariapsvs@hotmail.com

Thallyson Fellype Rangel Soares

ORCID: https://orcid.org/0000-0001-6171-3475

Universidade Federal de Campina Grande, Brasil

E-mail: thallysonrangel@hotmail.com

Guilherme Clarindo Marcos

ORCID: https://orcid.org/0000-0003-2977-5806

Universidade de Lisboa, Portugal

E-mail: oceanogui@gmail.com

Adriano Menino de Macêdo Júnior

ORCID: https://orcid.org/0000-0001-6367-1088

Centro Universitário Natalense, Brasil

E-mail: adrianomenino2016@gmail.com

\begin{abstract}
Resumo
Introdução: O HIV/AIDS é uma doença infectocontagiosa que acomete as células, T CD4, de defesa do organismo humano. Metodologia: O presente perfil epidemiológico de HIV/AIDS desenvolvido trata-se de um estudo transversal, no qual os presentes pesquisadores observaram os dados coletados e salvos do programa DataSUS e SINAN. Resultados: Observamos que em 2021 foram registrados 13.501 novos casos de HIV/AIDS no Brasil, desse total o sexo masculino notificou $71,8 \%(n=9.705)$, o sexo feminino com $28,6 \%(n=3.789)$; a população adepta da sexualidade Heterossexual registrou percentual de 18,7\% ( $\mathrm{n}=2.536)$, em segundo lugar os homossexuais com cerca de $10,5 \%(n=1.423)$ por HIV/AIDS; as idades de 40 a 59 anos com percentual de 21,6\% $(n=2.923), 25$ a 29 anos
\end{abstract}

\footnotetext{
${ }^{1} \mathrm{O}$ Trabalho foi orientado pelo pesquisador Adriano Menino de Macêdo Júnior, Farmacêutico - Generalista. Centro Universitário Natalense - UNICEUNA, ORCID: https://orcid.org/0000-0001-6367-1088, e-mail: adrianomenino2016@gmail.com.
} 
notificou $17,4 \%(n=2.350)$ e 30 a 34 anos, com percentual de $15,1 \%(n=2.045)$; a Região Sudeste, com $37,2 \%(n=$ 5.032), o Nordeste, com 22\% $(\mathrm{n}=2.982)$, e a Região Sul, percentuando 17,7\% $(\mathrm{n}=2.401)$ dos casos notificados; Os estados São Paulo, Rio de Janeiro e Rio Grande do Sul, notificaram os maiores casos da doença, na qual, respectivamente, seus percentuais de contagio foram: 18,3\% $(n=2.484), 10,4 \%(n=1.414)$ e 7,9\% $(n=1.067)$. Conclusão: Observamos que o sexo masculino foi o mais acometido, pela alta taxa de subnotificação na categoria de exposição, ficou impossível de revelar qual maior taxa de incidência do vírus nessa variável. Casos confirmados na faixa etária igual e superior a 60 anos preocupam autoridades da saúde pública e alerta para um possível "envelhecimento da epidemia".

Palavras-chave: HIV/AIDS; Saúde pública; Infecção; IST.

\begin{abstract}
Introduction: HIV/AIDS is an infectious disease that affects the CD4 $\mathrm{T}$ cells, the defense of the human body. Methodology: The present epidemiological profile of HIV/AIDS developed in this study is a cross-sectional study, in which the present researchers observed the data collected and saved from the DataSUS and SINAN programs. Results: We observed that in 2021 there were 13,501 new cases of HIV/AIDS in Brazil, of which 71.8\% were male $(n=9,705), 28.6 \%(n=3,789)$ of females; the population adept of Heterosexual sexuality registered a percentage of $18.7 \%(n=2,536)$, in second place the homosexuals with about 10.5\% $(n=1,423)$ for HIV/AIDS; ages 40 to 59 years old with a percentage of $21.6 \%(n=2,923), 25$ to 29 years old reported $17.4 \%(n=2,350)$ and 30 to 34 years old, with a percentage of $15.1 \%(n=2,045)$; the Southeast Region, with $37.2 \%(n=5,032)$, the Northeast, with $22 \%(n=2,982)$, and the South Region, accounting for $17.7 \%(n=2,401)$ of the reported cases; The states of São Paulo, Rio de Janeiro and Rio Grande do Sul reported the highest cases of the disease, in which, respectively, their percentages of contagion were: $18.3 \%(n=2,484), 10.4 \%(n=1,414)$ and $7.9 \%(n=1067)$. Conclusion: We observed that males were the most affected, due to the high rate of underreporting in the exposure category, it was impossible to reveal the highest incidence rate of the virus in this variable. Confirmed cases in the age group of 60 years and over worry public health authorities and warn of a possible "aging epidemic".
\end{abstract}

Keywords: HIV/AIDS; Public health; Infection; STI.

\title{
Resumen
}

Introdución: El VIH/SIDA es un virus que ataca el sistema inmunitario del cuerpo, más precisamente en las células T CD4, que son células de la defensa del organismo humano. Metodologia: El presente perfil epidemiológico de VIH/SIDA desarrollado, se trata de un estudio transversal en el cual los investigadores aquí involucrados, observaron los datos colectados y guardados del programa DataSUS y SINAN. Resultados: Observamos que en 2021 fueron registrados 13.501 nuevos casos de VIH/SIDA en Brasil, en este total el sexo masculino se resultó en un 71,8\% ( $\mathrm{n}=$ 9.705), el sexo femenino con $28,6 \%(n=3.789)$; en la población con de la sexualidad Heterosexual se registra un porcentaje de $18,7 \%(n=2.536)$, en segundo lugar los Homosexuales con un número alrededor de aproximadamente $10,5 \%(n=1.423)$ por VIH/SIDA; las edades de 40 a 59 años con 21,6\% $(n=2.923), 25$ a 29 años presenta un $17,4 \%$ $(\mathrm{n}=2.350)$ y de 30 a 34 años, con 15,1\% ( $\mathrm{n}=2.045)$; en la Región Sureste, con 37,2\% ( $\mathrm{n}=5.032)$, en Noreste, con $22 \%(n=2.982)$, y en la Región Sul, totalizando $17,7 \%(n=2.401)$ de los casos notificados; En los estados São Paulo, Rio de Janeiro y Rio Grande do Sul, se notifica los mayores casos de la enfermedad, en la cual, respectivamente, sus porcentajes de contagio fueron: $18,3 \%(n=2.484), 10,4 \%(n=1.414)$ y $7,9 \%(n=1.067)$. Conclusión: Observamos que el sexo masculino fue el que tiene más relevancia de casos presentados. No fue posible identificar cual mayor tasa de incidencia del vírus en esta variante. Casos confirmados en las edades igual y superior a 60 años preocupan autoridades de la salud pública y alerta para un posible "envejecimiento de la epidemia".

Palabras clave: VIH/SIDA; Salud pública; Infección; IST.

\section{Introdução}

A Síndrome da Imunodeficiência Humana Adquirida (AIDS) é uma doença causada pelo Vírus da Imunodeficiência Humana (HIV), no decorrer do texto doravante (HIV/AIDS), é uma doença infectocontagiosa que acomete todas as células de defesa do organismo humano, essas células são conhecidas como as "células da série branca do sangue", e também são denominadas de leucócitos. (Trindade et al, 2019, p. 154). No corpo humano há presença, de aproximadamente, 5 a 10 leucócitos para cada microlitro de sangue. São essas células mencionadas as responsáveis pela defesa de microrganismos invasores, que podem comprometer a saúde do seu corpo humano, então são normais os números de leucócitos aumentarem durante processos infecciosos.

Para nos aprofundarmos ainda mais, trazemos o pesquisador Levinson (2010, p. 325), quando afirma que "tanto o

HIV-1 como o HIV-2 causam AIDS; entretanto, HIV-1 é encontrado em escala mundial, enquanto HIV-2 é encontrado 
principalmente na África Ocidental." O HIV é um vírus intracelular obrigatório, sendo "um de dois importantes retrovírus linfotrópicos de células $\mathrm{T}$ humanas (o outro é o vírus da leucemia de células $\mathrm{T}$ humanas)." $\mathrm{O}$ alvo principal desses agentes são os linfócitos T (doravante T CD4+), que são infectados e mortos no organismo humano através da infecção, o que desencadeara "perda da imunidade mediada por células e em uma alta probabilidade de o hospedeiro desenvolver infecções oportunistas." Macrófagos e monócitos que possuem proteínas T CD4+ em seu exterior também podem ser acometidos. (Levinson, 2010, p. 325; Pieri; Laurenti, 2012). "O HIV pertence ao subgrupo de lentivírus dos retrovírus, responsáveis por infecções "lentas" com longos períodos de incubação", mas quando sua infecção se manifesta pode causas sintomas clínicos, como: "astenia, perda de peso, dermatose, deterioração do sistema imunológico e o sarcoma de Kaposi." (Levinson, 2010, p. 325; Pieri; Laurenti, 2012, p. 144; Araújo et al., 2021).

Assim informado a estrutura viral do HIV, explanaremos uma breve história do inicio da infecção mundial que perdura até os dias atuais. Na década de 80, um surto de casos de pneumonia por Pneumocystis acometeu a população da região de Los Angeles, Estados Unidos. Devido essa infecção pulmonar ser rara, se sabia que ela infectava, principalmente, pessoas imunossuprimidos. As equipes multiprofissionais da área da saúde relacionaram essas infecções respiratórias a uma incidência anômala de um tipo raro de câncer de pele e vasos sanguíneos, denominada de sarcoma de Kaposi. O perfil epidemiológico dos pacientes acometidos por essa infecção se enquadravam na categoria de exposição homossexual, ou seja, homens jovens que praticavam relação sexual com o mesmo sexo. Mas tarde, por volta de 1983, já era sabido que o vírus debilitava o sistema imune do corpo humano e tinha afinidade por células $\mathrm{T}$ auxiliares, nos dias atuais, conhecemos essa infecção como HIV/AIDS. (Macedo Júnior; Gomes, 2020; Silva et al., 2021).

De acordo com Dantas Carvalho et al. (2017), o Brasil notificou 656.701 casos, no período de 1980 até junho de 2012, de HIV/AIDS em todo o país. Desde a década de 80 o país vive uma epidemia, no ano de "2011 a taxa de incidência da doença chegou a 20,2 para cada 100 mil habitantes." (Dantas Carvalho et al., 2017, p. 23). O índice de contaminação no sexo masculino ainda é o que mais predomina. Em 1989, a probabilidade de contagio do sexo masculino era de 1:6, essas estatísticas não mudaram muito, pois de acordo com o último mapeamento feito até o ano de 2011, de casos HIV/AIDS, a probabilidade de contagio chegava "1,7 caso em homens para cada 1 em mulheres." (Dantas Carvalho et al., 2017, p. 23). Quem concorda com os dados de Dantas Carvalho et al., (2017), são os pesquisadores Luccas et al., (2021, p. 2), quando reafirmam que "no Brasil, no período entre 1980 e 2017, foram registrados nos sistemas de informações 911.271 casos de aids e 327.655 casos de óbitos por causa básica a aids".

No Brasil, por volta de 1980, surgiram os primeiros casos de infecção por HIV/AIDS, sendo o primeiro caso diagnosticado na cidade de São Paulo. Os primeiros casos da infeção ocorreram em pessoas homossexuais e pacientes que precisaram de transfusão sanguínea, por conseguinte em utentes de drogas injetáveis. (Godoy et al., 2008). Em 2005, já havia sido notificado 371.827 casos de HIV/AIDS, em detrimento de graves problemas sociais e sanitários do país, cerca de 46,2\% dos infectados pelo vírus, desde o inicio da epidemia, vieram a óbito. O HIV/AIDS não faz distinção de camadas sócias, ou seja, não importa sua idade, classe social, raça, a infecção somente atinge indivíduos com comportamentos de riscos: sexo sem proteção e troca de parceiros constantes e uso compartilhado de utensílios perfurocortantes (Pieri; Laurenti, 2012, p. 144).

Quando analisamos o cenário da infecção a nível internacional, estimasse que 4 milhões de pessoas convivam com o vírus do HIV, em todo o mundo, por isso a epidemia viral ainda não foi controlada, muito embora sua elevada taxa de mortalidade tenha sido reduzida, por meio da intensa força tarefa da indústria farmacêutica na criação de novos medicamentos antirretrovirais. Até o ano de 2015, estimasse controlar e reduzir a epidemia de HIV/AIDS em todo o mundo, sendo um dos oito objetivos milenares, e principais, de cada país. (Dantas Carvalho et al., 2017, p. 23).

Dados esses percentuais de contagio por HIV/AIDS em todo o mundo, e por se tratar de uma infecção sem cura, os cientistas Amorim e Duarte (2021, p. 2) alegam que o Programa Conjunto das Nações Unidas, é veemente no combate a 
epidemia, como podemos ver na citação a seguir:

[...] Em 2014, o Programa Conjunto das Nações Unidas sobre HIV/AIDS (UNAIDS) desenvolveu um ambicioso projeto de tratamento intitulado como 90-90-90, que tem a finalidade de acabar com a epidemia de AIDS até 2030. O projeto procura alcançar o objetivo através da realização de 3 metas até o ano de 2020: $90 \%$ de todas as pessoas que vivem com HIV conhecerem seu status sorológico; 90\% de todas as pessoas diagnosticadas com HIV receberem terapia antirretroviral sustentada (TARV); e $90 \%$ de todas as pessoas em TARV com status de supressão viral. O programa almeja não somente eliminar a doença, mas também proporcionar mais qualidade de vida para as Pessoas Vivendo com HIV (PVHIV), proporcionando tratamento para todos que necessitam, buscando um mundo mais justo e equitativo para as gerações futuras.

Seja em qualquer for a lugar do planeta, País, cidade, município, e suas respectivas regiões, o contagio e disseminação do vírus HIV/AIDS não ocorre apenas em homens que fazem sexo com outros homens (HSH), a acessão do HIV, nos países industrializados da América Latina, alcançou rapidamente a diversidade das camadas sociais, ou seja, mulheres, crianças, homens adeptos a relação e heterossexual, em seus mais variados contextos econômicos. Hoje, o paradigma de que o vírus HIV tem afinidade apenas pelos HSH, está sendo quebrado, é possível ver que a transmissão também se dá pela "via sangüínea, através do compartilhamento de seringas e agulhas por usuários de drogas injetáveis, em transfusões de sangue e hemoderivados e, ainda, pela via materno-infantil (transmissão da mãe para a criança na gestação, parto ou durante o aleitamento materno)". (Santos et al., 2002, p. 288; Goulart et al., 2021).

Dentro do contexto mencionado, durante a introdução, do que é o vírus HIV, da sua história, das formas de contagio, do mapeamento mundial dos casos positivos e de como o vírus é transmitido, é que delineamos nosso objetivo geral. O objetivo deste artigo é traçar o perfil epidemiológico da população brasileira e dos casos positivos de HIV/AIDS, durante todo o ano de 2021, com dados coletados do departamento de informática do Sistema Único de Saúde do Brasil (DataSUS) e Sistema de Informação de Agravos de Notificação (SINAN).

\section{Metodologia}

O presente perfil epidemiológico de HIV/AIDS desenvolvido trata-se de um estudo transversal, no qual os presentes pesquisadores observaram os dados coletados e salvos do programa DataSUS e SINAN. Para desenvolvermos os objetivos propostos, embasamo-nos numa perspectiva metodológica da pesquisa descritiva, que segundo o teórico Gil (2002, p. 41) se caracteriza como:

As pesquisas descritivas têm como objetivo primordial a descrição das características de determinada população ou fenômeno ou, então, o estabelecimento de relações entre variáveis. São inúmeros os estudos que podem ser classificados sob este título e uma de suas características mais significativas está na utilização de técnicas padronizadas de coleta de dados, tais como o questionário e a observação sistemática. (...) As pesquisas descritivas são, juntamente com as exploratórias, as que habitualmente realizam os pesquisadores sociais preocupados com a atuação prática. São também as mais solicitadas por organizações como instituições educacionais, empresas comerciais, partidos políticos etc. (Gil, 2002, p. 42).

Ao longo da pesquisa descritiva descrevemos o perfil epidemiológico de HIV/AIDS e da população brasileira que foi acometida durante o ano de 2021, o trabalho também tem natureza retrospectiva, já que utilizamos dados notificados da plataforma DataSUS, no respectivo ano. Ainda sobre o teórico Gil (2002), que classifica a pesquisa cientifica quanto aos procedimentos técnicos utilizados, o nosso trabalho classifica-se como bibliográfico, que para Gil (2002, p. 44-45):

A pesquisa bibliográfica é desenvolvida com base em material já elaborado, constituído principalmente de livros e artigos científicos. [...] Publicações periódicas são aquelas editadas em fascículos, em intervalos regulares ou irregulares, com a colaboração de vários autores, tratando de assuntos diversos, embora relacionados a um objetivo mais ou menos definido. As principais publicações periódicas são os jornais e as revistas. Estas últimas representam 
nos tempos atuais uma das mais importantes fontes bibliográficas. Enquanto a matéria dos jornais se caracteriza principalmente pela rapidez, a das revistas tende a ser muito mais profunda e mais bem elaborada.

Sendo assim, maior parte dos trabalhos utilizados para corroborar nossos achados, são artigos científicos oriundos de periódicos acadêmicos, a seguir informamos sua autoria, ano e título da obra, são eles, respectivamente:

- Amorim e Duarte (2021), "Perfil epidemiológico de casos notificados de HIV no estado de Goiás";

- Araújo et al. (2021), “Análise do perfil epidemiológico do número de casos de aids no Brasil nos últimos 10 anos";

- Brito, Castilho, Szwarcwald (2001), “AIDS e infecção pelo HIV no Brasil: uma epidemia multifacetada”;

- Godoy et al., (2008), “O perfil epidemiológico da aids em idosos utilizando sistemas de informações em saúde do datasus: realidades e desafios";

- Goulart et al. (2021), "Perfil epidemiológico de pacientes com HIV/AIDS no município de Campos dos Goytacazes, Rio de Janeiro";

- Júnior et al. (2019), "perfil epidemiológico hiv/aids no estado do Piauí em 2019”; soares (2014), "perfil epidemiológico e sócio demográfico dos pacientes vivendo com hiv/aids cadastrados no município de Vitória da Conquista/BA";

- Luccas et al. (2021), “Campanhas oficiais sobre hiv/aids no brasil: divergências entre conteúdos e o perfil epidemiológico do agravo";

- Pereira et al. (2018), "Epidemiologia do HIV e aids no estado do Rio Grande do Sul, 1980-2015";

- Santos e Assis (2011), "Vulnerabilidade das idosas ao HIV/AIDS: despertar das políticas públicas e profissionais de saúde no contexto da atenção integral: revisão de literatura";

- Santos et al. (2002), “A aids no Estado de São Paulo. As mudanças no perfil da epidemia e perspectivas da vigilância epidemiológica";

- Schuelter-Trevis (2013), "Perfil epidemiológico dos pacientes com HIV atendidos no sul do Estado de Santa Catarina, Brasil, em 2010";

- Silva et al. (2021), "Perfil epidemiológico de pacientes internados por HIV/AIDS no Brasil: Revisão integrativa da literatura";

- Trindade et al. (2019), "Perfil epidemiológico e análise de Tendência de HIV/AIDS/ Epidemiological profile and trend analysis of HIV/AIDS/ Perfil epidemiológico y análisis de tendencia del HIV/SIDA";

Todos os autores informados no estado da arte deste artigo dialogam e reafirmam os nossos resultados, traçados neste perfil epidemiológico de HIV/AIDS no período de 2021. É possível ver no trabalho impresso dos autores supracitados que de acordo com cada região do País a infecção de comporta na sociedade de uma maneira e os facilitadores de seu contagio, propagação e possíveis formas de contenção.

A partir do detalhamento metodológico que esse trabalho apresenta, realizamos a coleta dos dados notificados através da plataforma DataSUS, seguindo as abas: "Informações de Saúde (TABNET)", "Epidemiológicas e morbidade”, no grupo “Casos de Aids - Desde 1980 - SINAN”, selecionamos “Aids - desde 1980”, "Brasil por Região, UF e Município", no ano de 2020. As variáveis aplicadas e analisadas foram: "Sexo", "Categoria de Exposição", "Faixa etária", "Região de Residência" e "Unidade Federativa".

Este estudo envolveu apenas o levantamento de informações originadas de banco de dados de uso e acesso público DataSUS, o que justifica a ausência da apreciação de um Comitê de Ética, em conformidade com a Resolução nº 510/2016, em 
que não é necessário registrar no Comitê de Ética e Pesquisa com seres humanos aqueles estudos que utilizam dados de acesso público, domínio público e/ou que estejam em banco de dados sem possibilidade de identificação individual.

\section{Resultados e Discussão}

Este artigo mapeia o perfil epidemiológico de HIV/AIDS durante todo o ano de 2021, no Brasil, incluímos a seguir variáveis importantes a serem analisadas como: "Sexo da População Acometida", "Categoria de Exposição Hierárquica", "Faixa Etária", "Frequência por Região de Residência do Brasil", e "Unidade Federativa dos pacientes". Todos esses padrões identificam o comportamento da doença no meio da sociedade, bem como seus fatores relevantes de contagio.

Diante disso, de acordo com a Portaria de Consolidação no 4/GM/MS, de 28 de setembro de 2017, a "HIV/AIDS Infecção pelo Vírus da Imunodeficiência Humana ou Síndrome da Imunodeficiência Adquirida" está presente na Lista Nacional de Notificação Compulsória, e em caso de suspeita ou confirmação de infecção, a Secretaria Estadual de Saúde (SES) e Secretaria Municipal de Saúde (SMS) devem reportar, obrigatoriamente, em até uma semana os novos casos, para os órgãos competentes como, a organização das ações de Vigilância Epidemiológica, o Programa Nacional de Imunizações, afim de que tomem as medidas cabíveis para a sua contenção, tratamento e melhoria da qualidade de vida dos portadores da síndrome.

Com base na própria portaria, citada anteriormente, filtramos aqui os resultados desta pesquisa, e observamos que em 2021 foram registrados 13.501 novos casos de HIV/AIDS no Brasil, desse total o sexo masculino foi o mais acometido, notificando 71,8\% (n= 9.705), o sexo feminino registrou infecção de 28,6\% ( $\mathrm{n}=3.789)$. Dados disponíveis na Tabela 1 e no Gráfico 1.

Tabela 1. Casos confirmados de HIV/AIDS no Brasil, segundo o critério Sexo da população acometida, no período síncrono de 2021.

\begin{tabular}{ccccc}
\hline \multirow{2}{*}{$\begin{array}{c}\text { Diagnóstico } \\
\text { total 2021 }\end{array}$} & Masculino & Feminino & Em Branco & Total \\
\cline { 2 - 5 } & 9.705 & 3.789 & 7.000 & 13.501 \\
\hline $\mathbf{F r}$ & 0.719 & 0.281 & 0.001 & 1 \\
\hline$(\boldsymbol{\%})$ & 71.884 & 28.065 & 0.052 & 100 \\
\hline
\end{tabular}

Fonte: Elaborado pelos autores. 
Gráfico 2. Casos confirmados de HIV/AIDS no Brasil, segundo o critério Sexo da população acometida, no período síncrono de 2021.

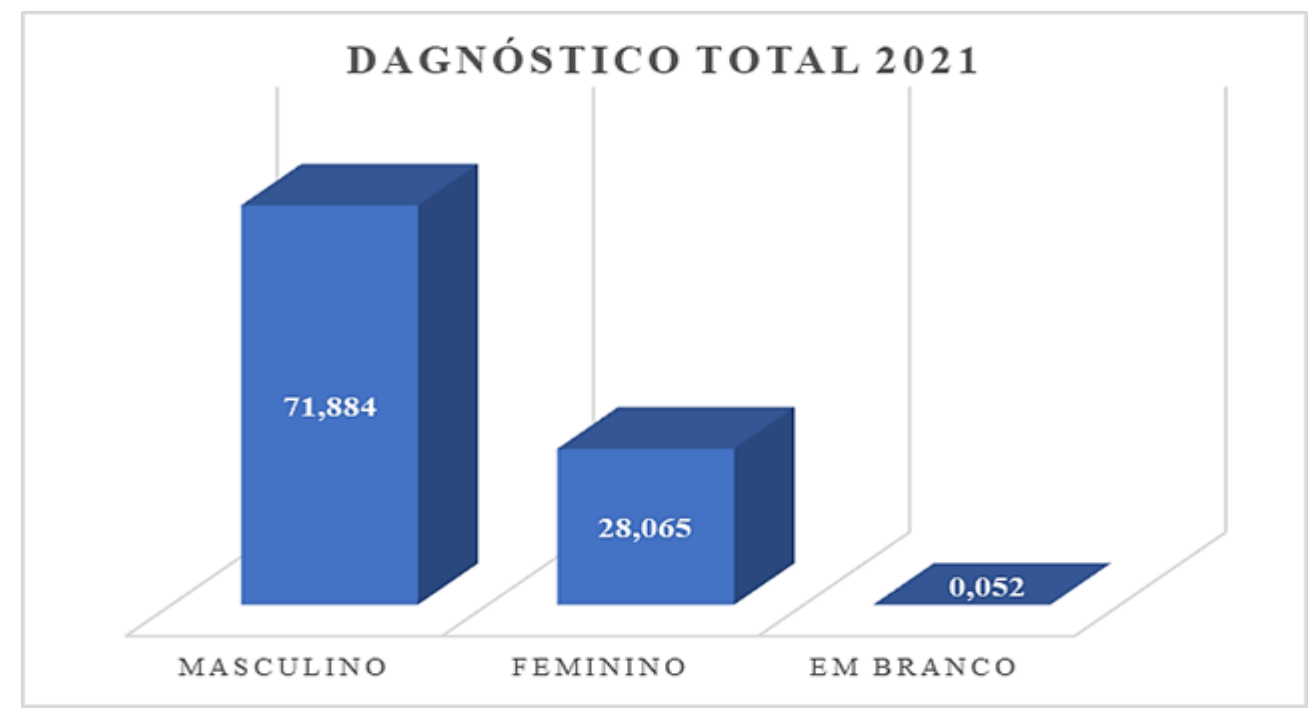

Fonte: Elaborado pelos autores.

O estudo, epidemiológico descritivo, de Godoy et al. (2008, p. 8), somou um total de 329.014 de novos casos de AIDS diagnosticados no período de 1995 a 2005, no município de Ribeirão Preto, localizado no Estado de São Paulo. Desse total observou-se que o sexo masculino teve maior número de diagnóstico, com 5.224, enquanto que o sexo feminino registrou 2.731 de novos casos para HIV/AIDS. Os autores ainda afirmam que "[...] em 1995 a média era de três homens diagnosticados para uma mulher diagnosticada (3:1). Já em 2005, a proporção diminuiu, sendo de 1,5 homem diagnosticado para uma mulher (1,5:1)." (Godoy et al., 2008, p. 8). Isso significa que o sexo masculino é o mais exposto à doença, se comparado ao sexo feminino. Vale ressaltar que durante a pesquisa de Godoy et al. (2008) a principal via de transmissão do vírus do HIV/AIDS foi por meio do contato sexual.

A pesquisa epidemiológica, transversal, descritiva-analítica e com abordagem quantitativa de Trindade et al. (2019), realizada no município de Montes Claros - MG, no período síncrono de tempo entre janeiro de 1986 e dezembro de 2016, analisou o perfil das pessoas portadoras de HIV/AIDS, um total de 523 casos confirmados. Cerca de 59,8\% ( $\mathrm{n}=313$ ) dos homens eram portadores do vírus.

De acordo com Brito, Castilho, Szwarcwald (2001) é de suma importância, que se haja nos estudos dos perfis epidemiológicos de populações portadoras de HIV/AIDS, a análise do gênero sexual, pois o estudo do sexo dos pacientes acometidos pela infecção pode ajudar na criação de novas políticas públicas, no caso do sexo masculino, maior enfoque na saúde do homem. Os autores ainda sugerem que campanhas de educação em saúde, podem prevenir o homem, principalmente, quando sensibiliza e conscientiza o uso da camisinha masculina.

Muito se sabe que no Brasil a falta de instrução escolar, o analfabetismo, a evasão escolar, etc., e a vulnerabilidade da economia do país contribuem para o aumento de casos de HIV/AIDS. Quanto mais à população tem acesso a informações e conhecimentos sobre doenças sexualmente transmissíveis maiores serão seus cuidados e proteções nos atos sexuais, diminuído até mesmo a propagação do vírus. (Trindade et al., 2019).

Após investigarmos o sexo da população acometida pelo HIV/AIDS, definimos que a população adepta da sexualidade Heterossexual foi a mais contaminada pela infecção supracitada, seu percentual chegou até $18,7 \%$ ( $n=2.536$ ), vale ressaltar que essa forma de atração física é realizada por homens e mulheres. Em segundo lugar, cerca de 10,5\% (n=1.423) dos Homossexuais do Brasil foram infectados pela epidemia de HIV/AIDS. Enfatizaremos aqui que o sistema do 
DataSUS/TABNET subnotificou 66,6\% $(n=8.999)$ do total dos casos, essa subnotificação acarreta um certo dano a nossa pesquisa, principalmente, no eu tange a variável aqui analisada "Categoria de Exposição. Hierárquica", e submetemos que nesse quantitativo subnotificado à mesclagem de todas as categorias. Contudo, os dados ainda são alarmantes e mostra que Brasil está longe de controlar essa epidemia. Dados disponíveis no Gráfico 2.

Ainda que os dados dessa variável, Categoria de Exposição Hierárquica, tenha sido subnotificada, o total de 13.501, é referente a notificações de casos confirmados, positivos, para o HIV/AIDS em todo o Brasil, nesse total está incluso toda a diversidade da população brasileira. Dados disponíveis na Tabela 2 e no Gráfico 2.

Tabela 2. Casos confirmados de HIV/AIDS no Brasil, segundo o critério Categoria de Exposição Hierárquica, no período síncrono de 2021 .

\begin{tabular}{ccccccccc}
\hline \multirow{2}{*}{$\begin{array}{c}\text { Diagnóstico } \\
\text { total 2021 }\end{array}$} & Homossexual & Bissexual & Heterossexual & UDI & $\begin{array}{c}\text { Transmissão } \\
\text { Vertical }\end{array}$ & Ignorado & Total \\
\cline { 2 - 8 } & 1.423 & 354 & 2.536 & 100 & 89 & 8.999 & 13.501 \\
\hline $\mathbf{F r}$ & 0.11 & 0.03 & 0.19 & 0.01 & 0.01 & 0.67 & 1 \\
\hline$(\%)$ & 10.54 & 2.62 & 18.78 & 0.74 & 0.66 & 66.65 & 100 \\
\hline
\end{tabular}

Fonte: Elaborado pelos autores.

Gráfico 2. Casos confirmados de HIV/AIDS no Brasil, segundo o critério Categoria de Exposição Hierárquica, no período síncrono de 2021.

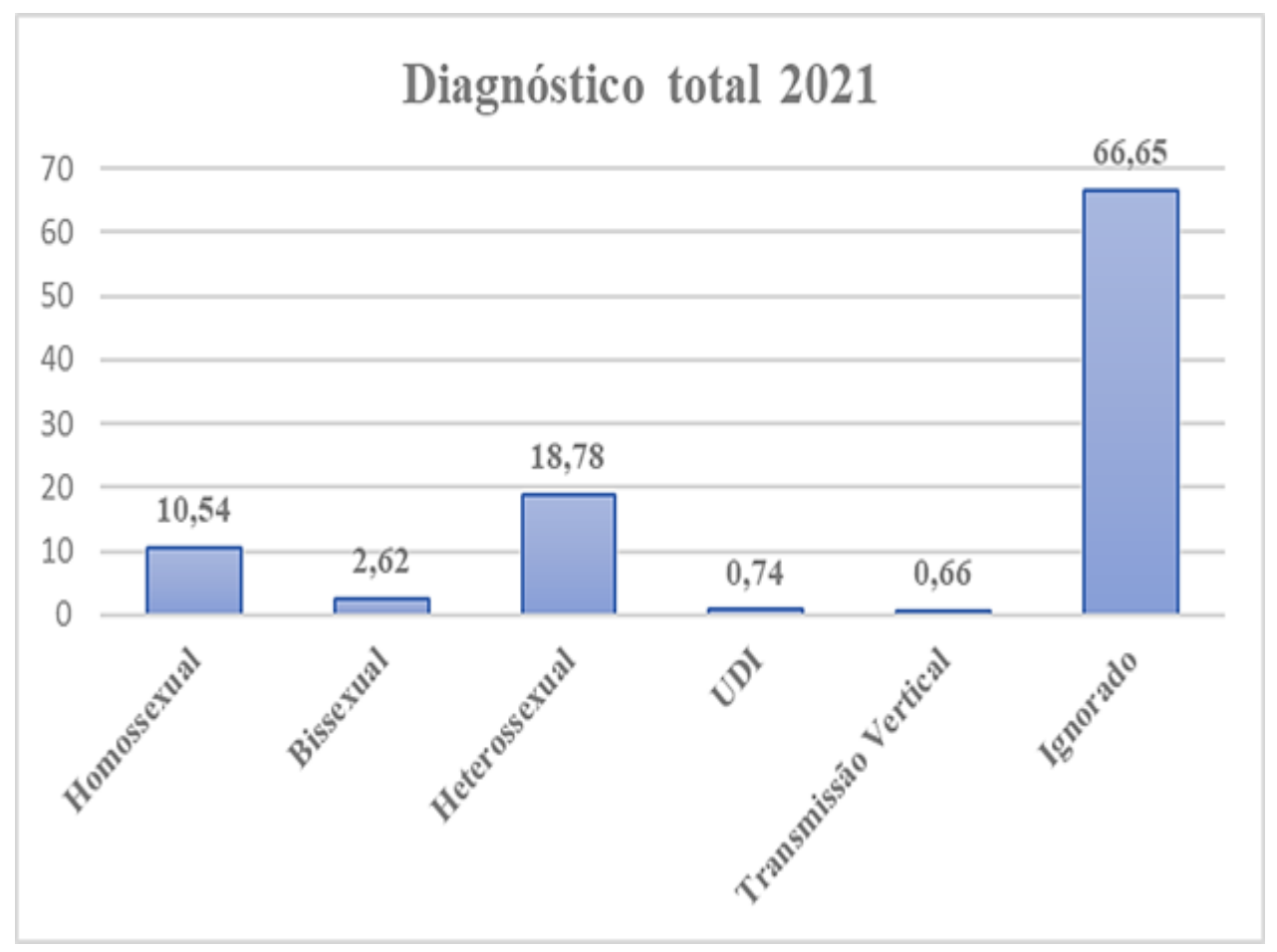

Fonte: Elaborado pelos autores.

Trindade et al. (2019) aponta no seu estudo que a categoria de exposição a infecção por HIV/AIDS, foi a do tipo heterossexual, assim sendo 253 casos. Os dados de Trindade et al. (2019) corroboram com os nossos, pois a maior parte notificada dos casos confirmados partiu da sexualidade heterossexual. Contudo, um grande número de casos nesse requisito foi subnotificado, cerca de $66,6 \%(n=8.999)$, o que coloca em cheque a confirmação desta variável. Trindade et al. (2019) elucida 
que, a categoria de exposição da infecção HIV/AIDS no Brasil, com o passar das décadas, começou a variar significativamente. É possível ver que no inicio da epidemia era mais comum que a relação homossexual fosse mais propensa ao contagio do vírus, com o passar dos anos esses paradigmas foram modificando, nos dias atuais a infecção pode ocorrer em varias categorias de exposição Os pesquisadores também concordam que a "transmissão heterossexual é a mais prevalente, o que contribui também para um aumento na prevalência no sexo feminino, processo esse que foi denominado de "heterossexualização" e "feminização"." (Trindade et al. 2019, p. 159).

Um trabalho importante que devemos mencionar aqui é o de Soares (2014, p 61), a pesquisadora afirma que desde o inicio da epidemia de HIV/AIDS, no Brasil, por volta da década de 80, a infecção foi dividida em três fases, a primeira fase, iniciada em 1980 seria "caracterizada pela infecção a grupos de homossexuais, bissexuais, receptores de sangue e hemoderivados." Já na segunda fase, iniciada por volta da década de 90, afirmasse que "a infecção foi identificada em usuários de drogas injetáveis e elevação na transmissão heterossexual." Por ultimo temos a terceira fase, que se estende até os dias atuais, e que observou-se "um aumento na transmissão por indivíduos heterossexuais, resultando em efetiva contaminação de mulheres." (Soares, 2014, p. 61). Essa constatação da autora mencionada corrobora com os dados desta pesquisa, uma vez que a categoria heterossexual teve acessão nas notificações compulsórias.

Diante desse cenário, dos elevado número nos casos confirmados de HIV/AIDS, na categoria heterossexual, Soares (2014, p. 61) alega que a mulher tem mais facilidade em se expor a infecção, do que os homens, uma vez que alguns fatores podem ser facilitadores, como "anatomia feminina, carga viral seminal, práticas de relações inseguras e desprotegidas, relações de poder e crença na fidelidade conjugal, atribuindo a heterossexualização como forma de transmissão confirmando a feminização da epidemia." (Soares, 2014, p. 61).

É possível também ver uma diminuição na transmissão de HIV/AIDS pela via vertical, como podemos ver nesta pesquisa, $0.6 \%(\mathrm{n}=89)$ dos casos foram por este contato, um número relativamente pequeno, uma vez que analisamos que esse total foi notificado em todo o Brasil durante o ano de 2021. Soares (2014, p. 61) afirmam que essa redução nos casos de HIV/AIDS pela transmissão vertical se dá pela "testagem anti-HIV, em decorrência da política de rastreamento e do tratamento de gestantes portadoras do vírus. Esta estratégia reduz a possibilidade da transmissibilidade, permitindo identificar o perfil sorológico." (Soares, 2014, p. 61).

Depois de explanadas aqui as variáveis "Sexo da População Acometida", "Categoria de Exposição Hierárquica", passamos, a seguir, traçar a "Faixa Etária" da população brasileira infectada por HIV/AIDS em 2021. Chamamos á atenção para as idades de 40 a 59 anos, com percentual de 21,6\% ( $n=2.923)$, a segunda faixa etária mais acometida foi a de 25 a 29 anos, que notificou $17,4 \%(n=2.350)$ e a terceira idade com índice de infecção elevada foi a de 30 a 34 anos, com percentual de $15,1 \%$ (n= 2.045). Dados disponíveis na tabela 3 e no Gráfico 3.

Tabela 3. Casos confirmados de HIV/AIDS no Brasil, segundo o critério Faixa Etária, no período síncrono de 2021.

\begin{tabular}{cccccccccccc}
\hline \multirow{2}{*}{$\begin{array}{c}\text { Diagnóstico } \\
\text { total 2021 }\end{array}$} & $\mathbf{<}$ & $\mathbf{5 - 1 2}$ & $\mathbf{1 3 - 1 9}$ & $\mathbf{2 0 - 2 4}$ & $\mathbf{2 5 - 2 9}$ & $\mathbf{3 0 - 3 4}$ & $\mathbf{3 5 - 3 9}$ & $\mathbf{4 0 - 4 9}$ & $\mathbf{5 0 - 5 9}$ & $>\mathbf{6 0}$ & Total \\
\cline { 2 - 11 } & 75 & 39 & 320 & 1.517 & 2.350 & 2.045 & 1.912 & 2.923 & 1.563 & 757 & 13.501 \\
\hline $\mathbf{F r}$ & 0.0 & 0.0 & 0.0 & 0.1 & 0.2 & 0.2 & 0.1 & 0.2 & 0.1 & 0.1 & 1 \\
\hline$(\boldsymbol{\%})$ & 0.6 & 0.3 & 2.4 & 11.2 & 17.4 & 15.1 & 14.2 & 21.7 & 11.6 & 5.6 & 100 \\
\hline
\end{tabular}

Fonte: Elaborado pelos autores. 
Gráfico 3. Casos confirmados de HIV/AIDS no Brasil, segundo o critério Faixa Etária, no período síncrono de 2021.

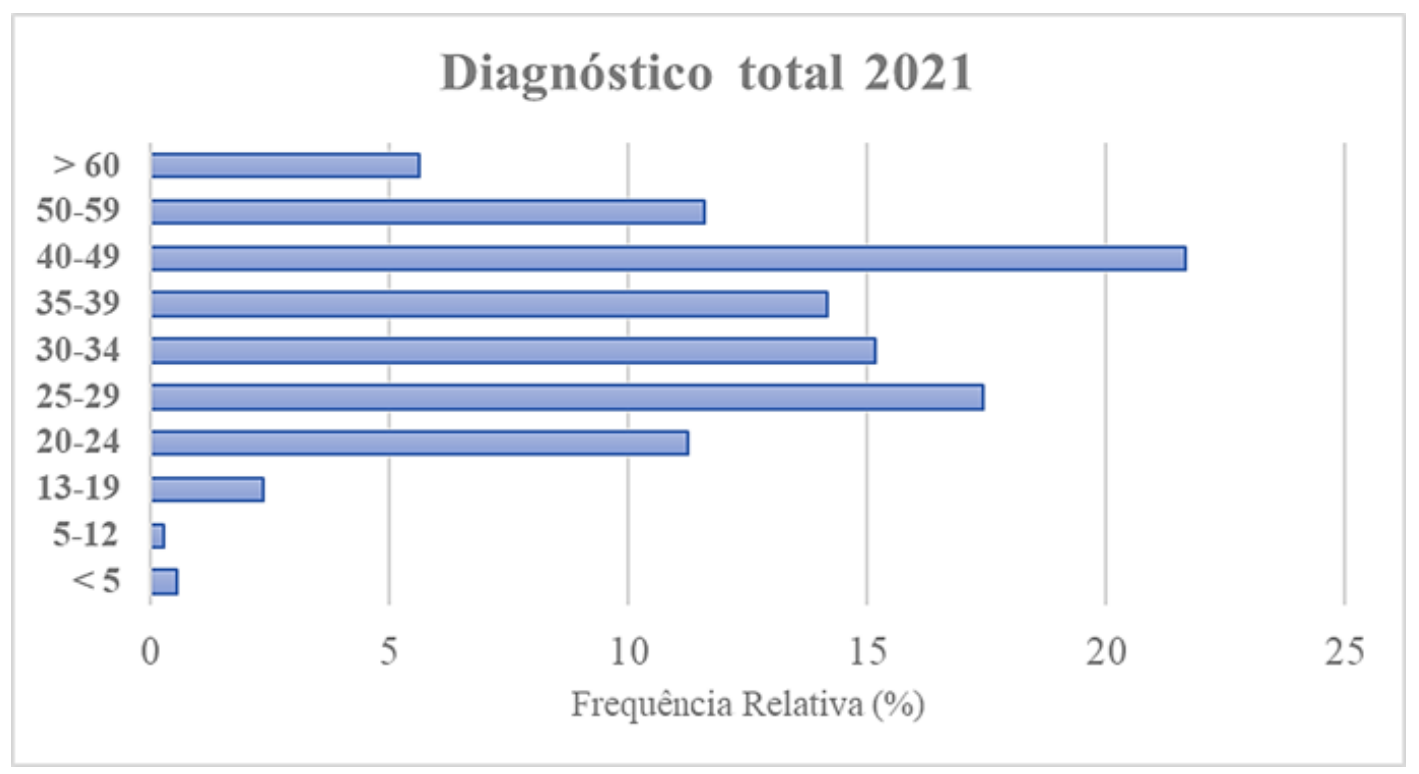

Fonte: Elaborado pelos autores.

No trabalho dos pesquisadores Godoy et al. (2008), já mencionados anteriormente, observou-se um aumento continuo, no período síncrono de tempo analisado, de contaminação em pessoas acima dos 60 anos de idade, o percentual foi de 2,42\% $(\mathrm{n}=7.955)$. (Godoy et al., 2008). Godoy et al. (2008, p. 10) afirmam que, ainda que o HIV/AIDS tenha menor porcentagem na população idosa, o número de novos casos diagnosticados da infecção se manteve contínuo de ano para ano, e alertam para uma nova fase da epidemia, ou seja, a mesma não está sendo estabilizada ou reduzida com o passar do tempo, isso significa que o aumento dos casos em idosos tem "sido denominado de leve envelhecimento da epidemia". Godoy et al. (2008) ainda sugerem que, indivíduos com idade de 30 a 39 anos são os mais acometidos pela doença, essa faixa etária corrobora com os achados da nossa pesquisa, uma vez que durante o período de 2021, pessoas com 25 a 49 anos de idade tiveram mais resultados positivos de HIV/AIDS em todo o Brasil, se comparado com as outras faixas etárias, é sabido que o vírus não faz distinção de pessoas nas suas mais variadas camadas sociais.

Consoante o estudo epidemiológico de Schuelter-Trevisol et al. (2010, p. 89), realizado nos utentes do "centro de Atendimento Especializado em Saúde (CAES), serviço de Saúde Pública de Tubarão-SC, analisou os diagnósticos positivos de HIV/AIDS no ano de 2010. Dos 476 prontuários investigados durante a pesquisa dos autores supracitados, destacamos que "a média de idade foi de 39,9 anos (DP $\pm 12,1)$, variando entre 1 e 79 anos de idade, e $272(58,2 \%)$ eram homens.” Ou seja, é nessa faixa etária que observamos um estacionamento e concentração da infecção por HIV/AIDS, como vimos também no estudo de Godoy et al. (2008). Se analisarmos o Boletim Epidemiológico viabilizado pelo Ministério da Saúde no período de 1980 até junho de 2011 observaremos que os casos de infecção da doença atingiu 397 mil homens contra 210 mil mulheres e faixa etária preeminente era a de 40-49 anos de idade.

Ainda que a faixa etária acima dos 60 anos de idade seja a menos propensa a contrair HIV/AIDS, durante a nossa pesquisa, com os dados coletados do DataSUS, e com as pesquisas da literatura, vemos que desde o inicio da epidemia há contaminação de idosos tem sido uma realidade. Nossa pesquisa sugere que em 2021, 5\% ( $n=757)$ dos idosos brasileiros testaram positivo para a infecção HIV/AIDS. Podemos então começar a romper tabus de que essa faixa etária, mais precisamente igual ou maior que 60 anos, não pratica a relação sexual. Desde o ano de 1999, os inibidores de fosfodiesterase-5 (PDE5) começaram a circular no mercado amplamente, pois se tratava do principal fármaco no combate a disfunção erétil. Consoante França (2019, p. 13), afirma que o uso do fármaco citado ajuda na "satisfação sexual, variáveis psicossociais 
elevadas (confiança, auto-estima, qualidade dos relacionamentos)", ou seja, de acordo com o estudo de Santos e Assis (2011), o acesso a essa medicação tem contribuído para o combate aos distúrbios eréteis, revelando assim a hipoatividade sexual masculina, consequentemente, o aumento de Infecções Sexualmente Transmissíveis (IST), e por conseguinte a infecção por HIV/AIDS.

De acordo com o estudo de Trindade et al. (2019, p. 157-158), é na fase do envelhecimento que o sistema imunológico do idoso começa a apresentar falhas fisiológicas, não conseguindo gerar defesa responsiva, em tempo hábil, contra microrganismos virulentos invasores. Os autores ainda sugerem que "sintomas inespecíficos como astenia e anorexia, comuns nesse ciclo de vida, dificultam o diagnóstico precoce de HIV/AIDS, logo retarda o tratamento". (Trindade et al., 2019, p. 157-158). De acordo com a literatura, muitos médicos não solicitam o exame anti-HIV 1 e 2 por medo de constranger pacientes idosos.

De acordo com a frequência Região de Residência do Brasil, o índice mais elevado foi na Região Sudeste, com 37,2\% $(n=5.032)$, a segunda região mais infectada pela epidemia de HIV/AIDS foi a do Nordeste, com 22\% ( $n=2.982)$, e a Região Sul, percentuando $17,7 \%(n=2.401)$ dos casos notificados. Dados disponíveis na Tabela 4 e no Gráfico 4.

Tabela 4. Casos confirmados de HIV/AIDS no Brasil de acordo com a Frequência por Região de Residência do Brasil, no período síncrono de 2021.

\begin{tabular}{ccccccc}
\hline \multirow{2}{*}{$\begin{array}{c}\text { Diagnóstico total } \\
\mathbf{2 0 2 1}\end{array}$} & $\begin{array}{c}\text { Região } \\
\text { Norte }\end{array}$ & $\begin{array}{c}\text { Região } \\
\text { Nordeste }\end{array}$ & $\begin{array}{c}\text { Região } \\
\text { Sudeste }\end{array}$ & \multicolumn{2}{c}{$\begin{array}{c}\text { Região } \\
\text { Sul }\end{array}$} & \multicolumn{2}{c}{$\begin{array}{c}\text { Região } \\
\text { Centro-Oeste }\end{array}$} & \begin{tabular}{c} 
Total \\
\cline { 2 - 7 }
\end{tabular} & 1.954 & 2.982 & 5.032 & 2.401 & 13.132 & 0,08 & 1 \\
\hline Fr & 0,14 & 0,22 & 0,37 & 0,18 & 8,38 & 100 \\
\hline$(\%)$ & 14,47 & 22,09 & 37,27 & 17,78 & \\
\hline
\end{tabular}

Fonte: Elaborado pelos autores. 
Gráfico 4. Casos confirmados de HIV/AIDS no Brasil de acordo com a Frequência por Região de Residência do Brasil, no período síncrono de 2021 .

\section{Diagnóstico total 2021}

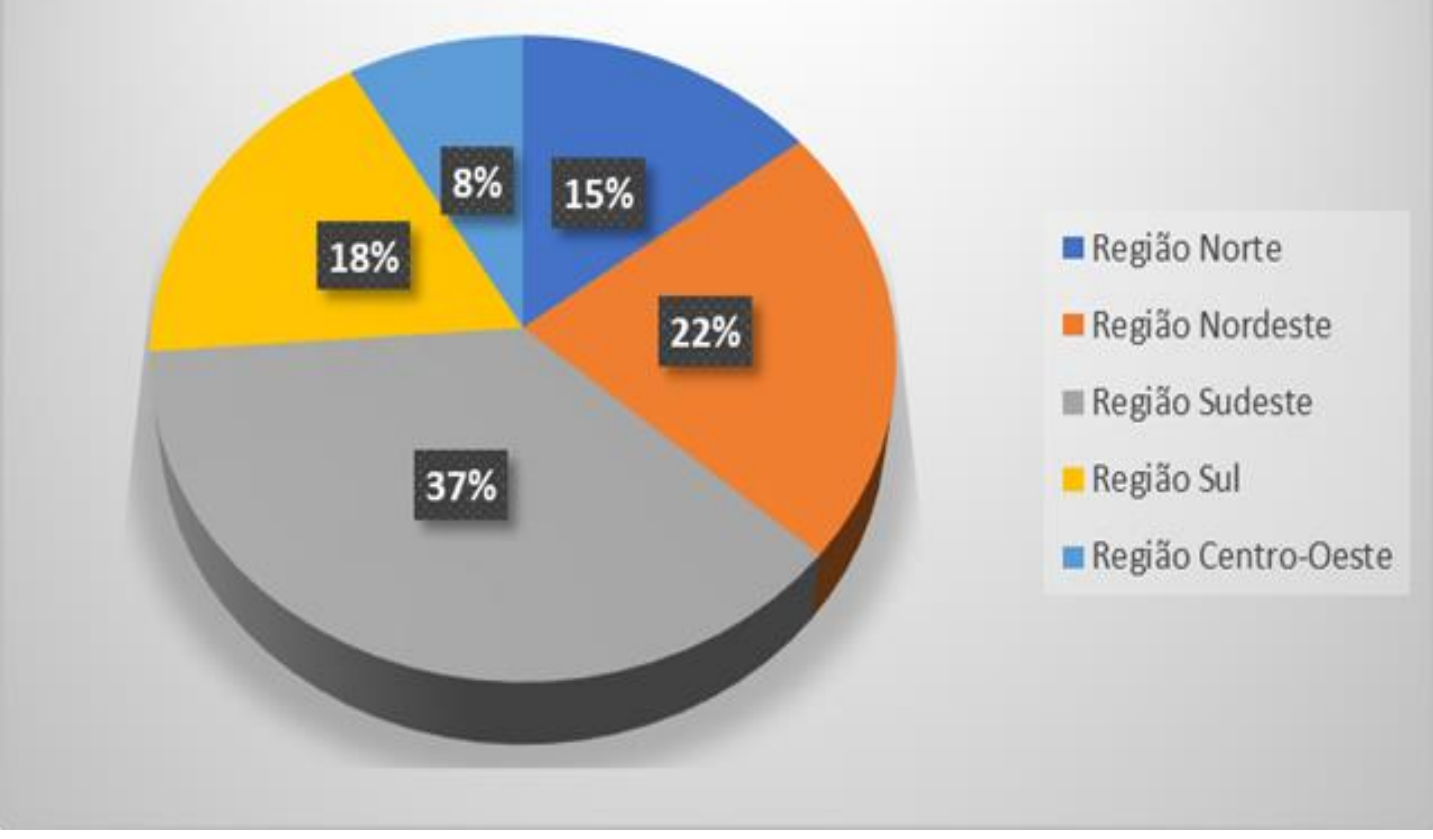

Fonte: Elaborado pelos autores.

A pesquisa de Godoy et al. (2008) suscita também similaridade com a nossa quando observamos os casos positivos de HIV/AIDS por Região de Residência. Os pesquisadores alegam que a Região Sudeste alcançou o percentual de $62,7 \%$ (n= 4.986) no período de sua investigação. Seus resultados corroboram com os nossos, pois em 2021 houve notificação de $37,2 \%$ $(n=5.032)$ novos casos de infecção para HIV/AIDS, mostrando que exclusivamente nessa Região o índice de contagio é bem maior se comparado com as demais. Podemos alegar que esse fator de contagio alto na Região Sudeste se deve por se tratar de uma das regiões mais desenvolvidas do Brasil, onde o turismo é alto, maior probabilidade de contrair infecção de fora e pelo não uso, e uso incorreto, do preservativo, a população residente é jovem, em idade de trabalho, e está em constante contato com o meio externo. Como podemos ver no Gráfico 5, a cidade de São Paulo, apresentou maior taxa de notificações positivas para HIV/AIDS, com 18,3\% $(n=2.484)$, e a cidade mencionada faz parte da Região Sudeste.

Consoante Júnior et al. (2019, p. 11) afirmam que, a Região Nordeste está "dentre os piores indicadores para" HIV/AIDS no país, o perfil da epidemiologia vem modificando, de décadas em décadas, o cenário da infecção através dos processos de "pauperização, envelhecimento, juvenização, heterossexualização, feminização e interiorização" o que corrobora para a quebra do paradigma de que a doença é mais propensa para determinados grupos sociais, o que na verdade, de fato, põese em cheque a "relação do vírus com a homossexualidade, promiscuidade e outros estigmas que permeiam a doença." Os achados de Júnior et al. (2019) corroboram com os dados desta pesquisa uma vez que a Região Nordeste foi a mais acometida, com 22\% (n= 2.982), pela infecção do HIV/AIDS no Brasil.

Por fim, mapeamos o perfil epidemiológico de HIV/AIDS no Brasil, segundo o critério unidade federativa, os estados São Paulo, Rio de Janeiro e Rio Grande do Sul, notificaram os maiores casos da doença, na qual, respectivamente, seus percentuais de contagio foram: 18,3\% $(\mathrm{n}=2.484), 10,4 \%(\mathrm{n}=1.414)$ e $7,9 \%(\mathrm{n}=1.067)$. Dados disponíveis na tabela 5 e no Gráfico 5. 
Tabela 5. Casos confirmados de HIV/AIDS no Brasil de acordo com a Frequência por Ano Diagnóstico e segundo UF Residência, no período síncrono de 2021.

\begin{tabular}{|c|c|c|c|}
\hline $\begin{array}{l}\text { UF Residência } \\
(\mathbf{2 0 2 1})\end{array}$ & $\mathbf{N}^{\mathbf{0}}$ & $\mathbf{F r}$ & $(\%)$ \\
\hline São Paulo & 2.484 & 0,18 & 18,40 \\
\hline Rio de Janeiro & 1.414 & 0,10 & 10,47 \\
\hline Rio Grande do Sul & 1.067 & 0,08 & 7,90 \\
\hline Minas Gerais & 894 & 0,07 & 6,62 \\
\hline Pará & 823 & 0,06 & 6,10 \\
\hline Amazonas & 749 & 0,06 & 5,55 \\
\hline Santa Catarina & 696 & 0,05 & 5,16 \\
\hline Bahia & 681 & 0,05 & 5,04 \\
\hline Paraná & 638 & 0,05 & 4,73 \\
\hline Pernambuco & 630 & 0,05 & 4,67 \\
\hline Goiás & 437 & 0,03 & 3,24 \\
\hline Ceará & 373 & 0,03 & 2,76 \\
\hline Maranhão & 359 & 0,03 & 2,66 \\
\hline Mato Grosso do Sul & 263 & 0,02 & 1,95 \\
\hline Mato Grosso & 244 & 0,02 & 1,81 \\
\hline Espírito Santo & 240 & 0,02 & 1,78 \\
\hline Alagoas & 234 & 0,02 & 1,73 \\
\hline Paraíba & 200 & 0,01 & 1,48 \\
\hline Distrito Federal & 188 & 0,01 & 1,39 \\
\hline Rio Grande do Norte & 187 & 0,01 & 1,39 \\
\hline Sergipe & 175 & 0,01 & 1,30 \\
\hline Piauí & 143 & 0,01 & 1,06 \\
\hline Rondônia & 126 & 0,01 & 0,93 \\
\hline Amapá & 86 & 0,01 & 0,64 \\
\hline Tocantins & 83 & 0,01 & 0,61 \\
\hline Roraima & 61 & 0,00 & 0,45 \\
\hline Acre & 26 & 0,00 & 0,19 \\
\hline TOTAL & 13.501 & 1 & 100 \\
\hline
\end{tabular}

Fonte: Elaborado pelos autores. 
Gráfico 5. Casos confirmados de HIV/AIDS no Brasil de acordo com a Frequência por Ano Diagnóstico e segundo UF Residência, no período síncrono de 2021.

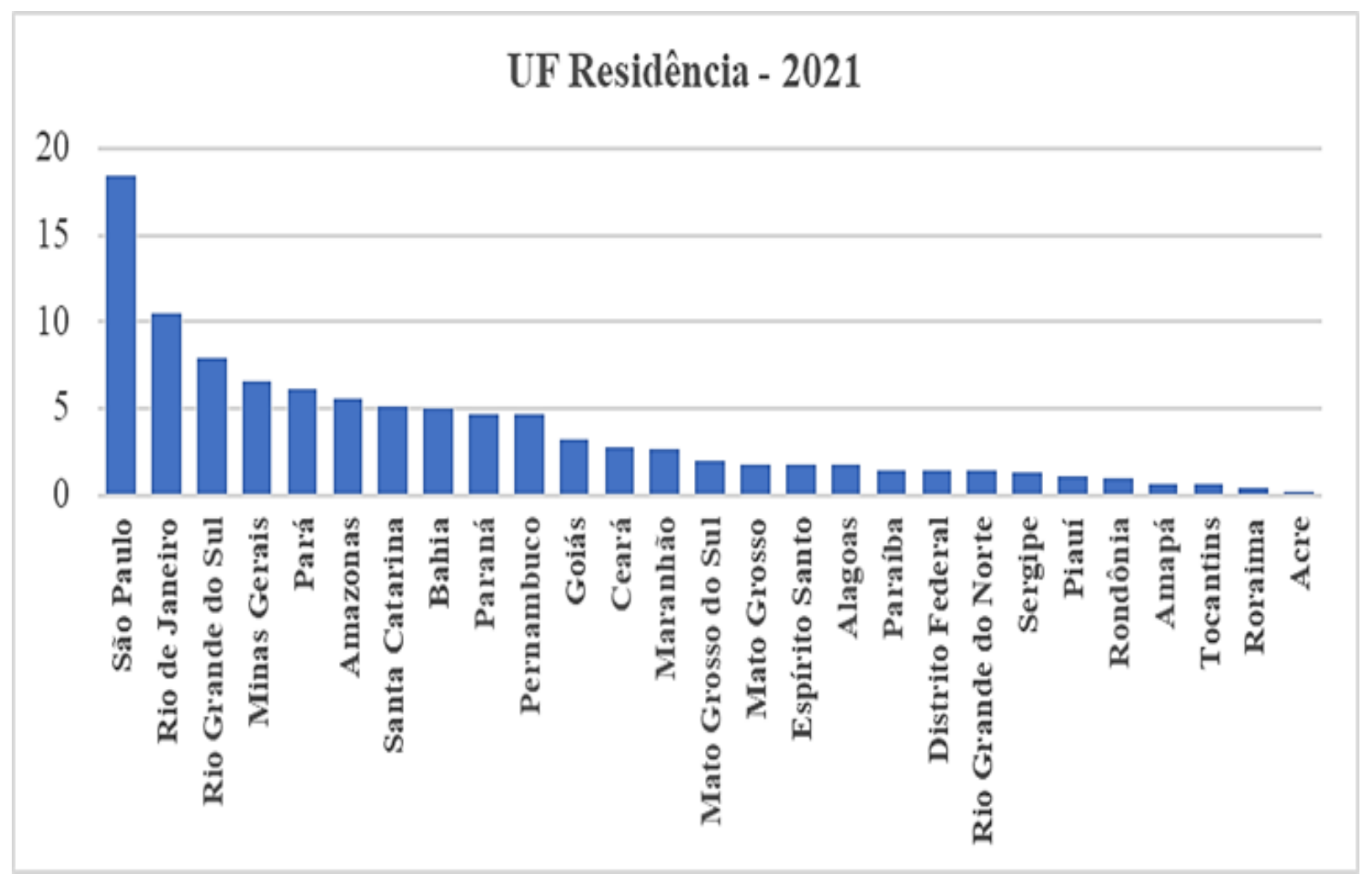

Fonte: Elaborado pelos autores.

De acordo com a pesquisa de Santos et al. (2002), a infecção causada pelo HIV/AIDS tem acometido pelo menos 50\% de toda a população brasileira, ou seja, muitas tem sido as notificações de casos confirmados do vírus nesse Estado. Os autores afirmam é "o município de São Paulo o que apresenta o maior número absoluto de casos de aids no Brasil, como seria de se esperar, dada a sua densidade populacional e suas demais características de grande centro urbano." (Santos et al., 2002, p. 290). O percentual de HIV/AIDS até a data de 31/12/2001 no Estado de São Paulo registrou 106.873 casos e destes $44 \%$ (47.047 casos) são residentes no Município de São Paulo. (Santos et al., 2002, p. 290).

Santos et al. (2002, p. 291) ainda afirmam que, só no Estado de São Paulo, no período de 1980 a 2001 foram notificados o total de 185.771 casos de HIV/AIDS em todo Estado de São Paulo. Os autores calcularam o coeficiente de incidência por 100.000 habitantes. Esses achados de Santos et al. (2002) corroboram com os desta pesquisa, quando analisamos os nossos resultados, no qual São Paulo marcou 18,3\% ( $\mathrm{n}=2.484)$ de casos de HIV/AIDS no ano de 2021 , sendo o local que mais notifica a infecção atualmente.

Como mencionado anteriormente, o Rio grande do Sul é o terceiro Estado que mais notificou casos positivos de HIV/AIDS no Brasil, sendo 7,9\% ( $\mathrm{n}=1.067)$, a pesquisa que dialoga com nossos resultados é a de Pereira et al. (2018). O estudo descritivo dos autores, realizado no período síncrono de 1980 até 2015, registrou 83.313 casos de HIV/AIDS, logo “as taxas de detecção de aids por 100 mil habitantes aumentaram de 1,1 (1.051) caso, no período de 1980 a 1990, para 40,3 (65.497) casos no período de 2001 a 2015.” O estado apresentou constante contaminação pela infecção, no período de tempo informado, o Rio Grande do Sul é o estado que notifica duas vezes mais no país casos de HIV/AIDS, principalmente em regiões metropolitanas, mesmo com a existência e ampla distribuição da terapia antirretroviral para a população, assim diz Pereira et al. (2018, p. 8). 
O estudo transversal de Carvalho Dantas et al. (2017), realizado na cidade de Rio das Ostras, Estado do Rio de Janeiro, nos anos de 2010 e 2011, também dialoga com os nossos resultados, os pesquisadores analisaram 232 prontuários de casos positivos de HIV/AIDS, e afirmam que a regiões metropolitanas Sudeste e Sul tinham forte índice de contágio em meados da década de 80. Carvalho et al. (2017, p. 26), afirmam que "a interiorização da AIDS é resultante do aumento no número de indivíduos infectados e da expansão da área de abrangência da epidemia para municípios de médio e pequeno porte, que começavam a detectar novos casos de infecção pelo HIV entre sua população" o que ocorre no Estado do Rio de Janeiro. (Carvalho et al., 2017, p. 26).

Uma pesquisa realizada no Estado do Piauí, Região Nordeste do Brasil, conduzida pelos pesquisadores Júnior et al. (2019, p. 9), registrou 207 novos casos de HIV/AIDS, os autores apontam que a incidência no ano foi de "6,32 novos casos/100.000 habitantes." Piaú também registrou, no mesmo ano da pesquisa dos autores, 134 óbitos causado pela infecção HIV/AIDS, "o que representa 4,08 óbitos por HIV a cada 100.000 habitantes. Ao passo que, 3,08 óbitos por HIV são do sexo masculino para 01 óbito do sexo feminino.” (Júnior et al., 2019, p. 11-12).

\section{Conclusão}

A critério de argumentar a favor da nossa pesquisa, defendo aqui que às pesquisas de perfis epidemiológicos, com dados divulgados e mantidos em banco de informações de domínio público, possuem segurança e veracidade em expor os fatos, bem como podem minimizar custos e tempo dos cientistas e envolvidos, além de ser uma fonte de encorajamento na criação de novas políticas públicas.

Na presente pesquisa, com auxilio das plataformas do DataSUS, TABNET e SINAM, podemos criar um panorama epidemiológico dos novos casos de HIV/AIDS diagnosticados no Brasil em 2021. No que tange as variáveis aqui utilizadas, estas supracitadas na metodologia, justificamos a importância das equipes multiprofissionais de vigilância em saúde, reelaborarem suas praticas de educação em saúde, redirecionarem investimentos capitais para está área de pesquisa e conhecimento, e, por conseguinte mobilizar os gestores públicos no planejamento estratégico para prevenir, controlar e combater a epidemia HIV/AIDS.

O perfil epidemiológico de HIV/AIDS ficou marcado por um cenário preocupante, observamos que o sexo masculino foi o mais acometido, pela alta taxa de subnotificação na categoria de exposição, ficou impossível de revelar qual maior taxa de incidência do vírus nessa variável, contudo, os dados totais aqui se referem a casos positivos, só não tivemos como evidenciar, precisamente, a categoria de exposição mais acometida pela infecção. Mesmo que a faixa etária mais infectada seja a jovens, entre 25 a 49 anos, temos uma minoria com idade igual e superior a 60 anos, o que preocupa também as autoridades de saúde pública, para um possível "envelhecimento da epidemia".

\section{Agradecimentos}

Quero agradecer a Izabella Julia Evora, discente do Curso de Letras Língua Portuguesa, da Universidade do Estado do Rio Grande do Norte - RN, pelo seu empenho e colaboração na tradução do nosso resumo, escrito na Língua Portuguesa, para a Língua Inglesa. Agradecimentos também a estudante de medicina, Nayara Rayane Fernandes da Silva, da Universidad Nacional de La Plata - UNLP, pela tradução do nosso resumo, escrito na Língua Portuguesa, para a Língua Espanhola.

\section{Referências}

Amorim, T. F., \& da Silva Duarte, L. (2021). Perfil epidemiológico de casos notificados de HIV no estado de Goiás. Revista Científica da Escola Estadual de Saúde Pública de Goiás" Cândido Santiago", 7, e7000043-e7000043. 
Araújo, D. A. M., Júnior, D. N. V., do Nascimento, J. M. F., de Carvalho, J. A. R., Brito, V. R. R., \& Sousa, L. R. M. (2021). Análise do perfil epidemiológico do número de casos de aids no Brasil nos últimos 10 anos. Saúde Coletiva (Barueri), 11(65), 6054-6065. http://www.revistas.mpmcomunicacao.com.br/index.php/saudecoletiva/article/view/1590/1833.

BRASIL. Portaria n ${ }^{\circ}$ 204, de 17 de fevereiro de 2016. Lista Nacional de Notificação Compulsória de doenças, agravos e eventos de saúde pública nos serviços de saúde públicos e privados em todo o nacional, nos termos do anexo, e dá outras providências. Diário Oficial da União, Brasília, DF, n. 32, revogando a

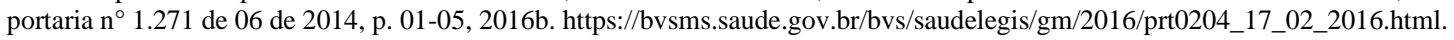

Brito, A. M. D., Castilho, E. A. D., \& Szwarcwald, C. L. (2001). AIDS e infecção pelo HIV no Brasil: uma epidemia multifacetada. Revista da sociedade brasileira de medicina tropical, 34, 207-217. https://www.scielo.br/j/rsbmt/a/zBSKHBDyfvfz7cLQp7fsSBg/?lang=pt.

Carvalho Dantas, C., Dantas, F. C., Monteiro, B. A. C., \& Leite, J. L. (2017). Perfil epidemiológico dos pacientes com HIV atendidos em um centro de saúde da região litorânea do estado de Rio de Janeiro, Brasil, 2010-2011. Arquivos Catarinenses de Medicina, 46(1), 22-32. http://www.acm.org.br/acm/seer/index.php/arquivos/article/view/250.

França, I. M. B. D (2019). Automedicação do Tadalafila em idosos e sua repercussão na qualidade de vida. Orientadora: Profa. Ma. Emilly Souza Marques. Trabalho de Conclusão de Curso - Faculdade CESMAC do Sertão, Alagoas, 2019. https://ri.cesmac.edu.br/handle/tede/569.

Gil, AC (2002). Como elabora projetos de pesquisa/Antônio Carlos Gil. (4a ed.), Atlas.

Godoy, V. S., Ferreira, M. D., Silva, E. C., Gir, E., \& Canini, S. R. M. S. (2008). O perfil epidemiológico da aids em idosos utilizando sistemas de informações em saúde do DATASUS: realidades e desafios. DST J Bras Doenças Sex Transm, 20(1), 7-11. http://ole.uff.br/wpcontent/uploads/sites/303/2018/02/r20-1-2008-1.pdf.

Goulart, M. S., da Silva Polidoro, T., Júnior, V. M. V., de Castro Palermo, T. A., Silva, A. T. M. F., Totti, M. E. F., \& dos Santos, C. M. (2021). Perfil epidemiológico de pacientes com HIV/AIDS no município de Campos dos Goytacazes, Rio de Janeiro. Revista de Saúde Coletiva da UEFS, 11(2), e7347e7347.

Júnior, I. G. C., Ribeiro, S. J. S., do Nascimento, J. M. F., Soares, T., \& Júnior, D. N. V. (2022). Perfil Epidemiológico Hiv/Aids No Estado Do Piauí Em 2019. Revista Ciência Plural, 8(1), e25682-e25682. https://periodicos.ufrn.br/rcp/article/view/25682.

Levinson, W. (2010). Microbiologia médica e imunologia. Warren Levinson; tradução: Martha Maria Macedo Kyaw. (10a ed.), AMGH.

Luccas, D. S. D., Brandão, M. L., Limas, F. M., Chaves, M. M. N., \& Albuquerque, G. S. C. D. (2021). Campanhas oficiais sobre hiv/aids no brasil: divergências entre conteúdos e o perfil epidemiológico do agravo. Cogitare Enfermagem, 26.

Macedo Júnior, A.M. Gomes, J. T. Estudo Epidemiológico da AIDS no Brasil - BR, No Período de 2015-2019, A sua História e Políticas Públicas Criadas Até os Dias Atuais. (2020). Temas em saúde, 20(4), 256-283.

Ministério da Saúde. Departamento de AIDS, DST e Hepatites virais. Hepatites Virais. Bol. Epidemiol. 2010; 8(1), 1-164. www.aids.gov.br.

Pereira, G. F. M., Shimizu, H. E., Bermudez, X. P., \& Hamann, E. M. (2018). Epidemiologia do HIV e aids no estado do Rio Grande do Sul, $1980-2015$. Epidemiologia e Serviços de Saúde, 27. https://www.scielo.br/j/ress/a/dYTjGC34SVZRGfbKYLJG9yn/?lang=pt.

Pieri, F. M., \& Laurenti, R. (2012). HIV/AIDS: perfil epidemiológico de adultos internados em hospital universitário. Ciência, Cuidado e Saúde, 11, 144-152. https://periodicos.uem.br/ojs/index.php/CiencCuidSaude/article/view/17069. Acessado em: 16 de janeiro de 2022.

Santos, A. F. D. M., \& Assis, M. D. (2011). Vulnerabilidade das idosas ao HIV/AIDS: despertar das políticas públicas e profissionais de saúde no contexto da atenção integral: revisão de literatura. Revista Brasileira de Geriatria e Gerontologia, 14 , 147-157. https://www.scielo.br/j/rbgg/a/wZdvVxsF3vCYLnS5nmLcCLm/abstract/?lang=pt\&format=html.

Santos, NJS, Tayra, A., Silva, SR, Buchalla, CM, \& Laurenti, R. (2002). A aids no Estado de São Paulo: as mudanças no perfil da epidemia e perspectivas da vigilância epidemiológica. Revista Brasileira 286-310. https://www.scielo.br/j/rbepid/a/fxLpx7RVMYnpmvsyCwvZPWF/abstract/?lang=pt.

Schuelter-Trevisol, F., Paolla, P., Justino, A. Z., Pucci, N., \& Silva, A. C. B. D. (2013). Perfil epidemiológico dos pacientes com HIV atendidos no sul do Estado de Santa Catarina, Brasil, em 2010. Epidemiologia e Serviços de Saúde, 22(1), 87-94. http://scielo.iec.gov.br/scielo.php?pid=S167949742013000100009\&script=sci_abstract.

Silva, D. G., Lima, R. C. C., de Oliveira, F. G., Otero, S. G., Natário, R. M., Pereira, L. T. T., \& dos Santos, M. L. F. (2021). Perfil epidemiológico de pacientes internados por HIV/AIDS no Brasil: Revisão integrativa da literatura. Research, Society and Development, 10(9), e19410917976-e19410917976.

Soares, F. N. S. (2014). Perfil epidemiológico e sócio demográfico dos pacientes vivendo com HIV/AIDS cadastrados no município de Vitória da Conquista/BA. Revista Saúde. Com, 10(1), 54-63. https://periodicos2.uesb.br/index.php/rsc/article/view/282.

Trindade, F. F., Fernandes, G. T., Nascimento, R. H. F., Jabbur, I. F. G., \& de Souza Cardoso, A. (2019). Perfil epidemiológico e análise de Tendência de HIV/AIDS/Epidemiological profile and trend analysis of HIV/AIDS/Perfil epidemiológico y análisis de tendencia del HIV/SIDA. Journal Health NPEPS, 4(1), 153-165. https://periodicos.unemat.br/index.php/jhnpeps/article/view/3394. 